\title{
Las estrellas de Hollywood como prescriptores en el spot publicitario: un activo para las marcas y anunciantes
}

\author{
Juana TAVERAS SuERo ${ }^{1}$ \\ Universidad Camilo José Cela
}

Recibido: $18 / 02 / 2014$

Aceptado: 26/06/2014

\begin{abstract}
Resumen
Es cierto que el prescriptor se caracteriza por recomendar y hablar bien sobre las cualidades y beneficios de una marca, producto o servicio. Sin embargo, dada la sociedad postmoderna en la que vivimos, concebimos, que la publicidad con estrella cinematográfica se sirve de un concepto narrativo más indirecto, al punto que casi parece que no hay prescripción. Con lo cual, el artículo, a partir del análisis de una muestra de 41 spots sostiene, que la notoriedad, la transtextualidad y el poder mítico de la estrella hollywoodense son las razones que llevan a las marcas a contratar actores de Hollywood y rodar spots que renuncian a la prescripción directa por otra sostenida sobre lo que en Narratología se llama, instancias enunciadoras o discursivas, donde el autor/es (para nosotros el actor), el autor implícito (para nosotros la estrella) y el personaje de la historia, intervienen para transmitir la idea del anunciante. Se trata de explicar, además, cómo el famoso se beneficia del reconocimiento de las marcas y las marcas de la notoriedad e imagen del prescriptor. Notoriedad, transtextualidad y poder mítico se convierten para la marca en lo que Aaker (2002) llama activos. Ello nos obligará a determinar: la notoriedad del actor en equivalencia con la marca, rasgos y roles del personajes y la imagen de la estrella. Lo que sucede a estos tres niveles favorece la venta del objeto anunciado y, al mismo tiempo, se produce una confluencia entre estos elementos narrativos y la notoriedad, identidad y valores de marca.
\end{abstract}

Palabras claves: prescriptor, estrella, spot publicitario, instancias enunciadoras, activos.

\footnotetext{
${ }^{1}$ Doctoranda del programa de doctorado en Publicidad y Relaciones Públicas de la Universidad Camilo José Cela. E-mail: joanatave@gmail.com.
} 


\title{
Hollywood stars such as prescribers in the advertising spot: an asset for brands and advertisers
}

\begin{abstract}
It is true that the prescriber is characterized by recommending and speak well about the qualities and benefits of a brand, product or service. However, given the postmodern society in which we live we conceive that advertising with film star uses a more indirect narrative concept, to the point that almost seems no prescription. Whereupon, the article, based on an analysis of a sample of 41 spots argues that reputation, transtextuality and mythic power of the Hollywood star are the reasons leading brands to engage actors in Hollywood and roll spots that waive the requirement for another sustained direct what is called in Narratology enunciadoras or discursive instances where the author / $\mathrm{s}$ (for us the actor), the implied author (for us the star) and the character of the story, involved convey the idea of the advertiser. This is explained further how the famous benefits of brand recognition and brand awareness and image of the prescriber. Notoriety, transtextualidad and power become legendary for the brand in what Aaker (2002) active calls. This will force us to determine: the reputation of the actor on par with the brand, features and roles of characters and the image of the star. What happens to these three levels favors announced the sale of the object and at the same time, a confluence between these narrative elements and visibility, identity and brand values occurs.
\end{abstract}

Keywords: prescribing, star, advertising spot, enunciadoras instances, active.

\section{Introducción}

Las aportaciones de Genette $(1998)^{2}$ sobre el discurso del relato, indican que en la producción de un enunciado o texto, participan varias entidades con funciones visiblemente narrativas. El relato se permite involucrar a alguien o diferentes entidades que se encarguen de contar la historia. A estas entidades se les denomina desde la narrativa fílmica, instancias enunciadoras o discursivas ${ }^{3}$. Son las encargadas de organizar el texto. Por tanto, del «mismo modo, que el texto narrativo emplea una instancia enunciadora para contar una historia» ${ }^{4}$ consideramos que con la utilización del prescriptor que mostramos, el mensaje publicitario se organiza en torno a tres instancias enunciadoras o discursivas: El autor/actor, autor implícito/la estrella, y la instancia del prescriptor como narrador y personaje. Esta hipótesis nos obliga analizar en distintas capas en qué consiste cada una de estas instancias, en qué beneficia lo anunciado y cómo se presenta en la organización del texto (spot). Con lo cual, la hipótesis que versa en considerar al actor como autor, trata primero de explicar, que el hecho de que un spot sea una obra creativa colectiva, no impide que aquí consideremos como tales autores a los actores. Legalmente así están reconocidos. Tienen, por ejemplo, su derecho de

\footnotetext{
${ }^{2}$ Genette, G. (1998). Nuevo discurso del relato, Madrid, Cátedra.

${ }^{3}$ Diez Puertas, E. (2006). Narrativa filmica: Escribir la pantalla, pensar la imagen (2a ed.), Madrid, Fundamentos.

${ }^{4}$ García Jiménez, J. (1996). Narrativa audiovisual (2a ed.), Madrid, Cátedra, S.A, 136.
} 
imagen ${ }^{5}$. Porque ¿qué es un autor?, el término designa a una entidad de muy amplia proyección. Se llama autor,

[...] al escritor que trabaja sus propias palabras [...] en literatura la noción de autor presupone un hombre de oficio estimulado por el afán de crear y sobre todo de haber creado. La categoría de autor es la del escritor que pone todo su oficio, todo su pasado de información literaria y artística, todo su caudal de conocimientos e ideas al servicio del sentido unitario de la obra que elabora. ${ }^{6}$

El autor, es una entidad real y empírica. Es la persona que interviene en la creación de la obra. Pero, como hemos señalado, dado que en el spot no existe un solo autor sino varios, para nosotros esa entidad real (que actúa de prescriptor) en los textos publicitarios, es el actor, ya que su vida personal también puede estar presente en el spot. Es más, como tal, el autor tiene una notoriedad social que surge de los premios recibidos por su trabajo, de su formación intelectual y artística, de una trayectoria más o menos larga o de su sueldo más o menos alto. Se le contrata por todo eso, ya que, el prescriptor al ser «aquella persona cuya recomendación de un producto o servicio puede tener influencia sobre los consumidores» ${ }^{7} \mathrm{y}$ 《aquel personaje que respalda el producto anunciado como experto, famoso o figurante $\rangle^{8}$ debe disfrutar de ciertos atributos que le señalen como un sujeto dotado para ejercer influencia sobre las decisiones del público consumidor y ser visto como un activo para las marcas y los anunciantes. Pues ninguna marca contrataría como prescriptor a un actor sin un solo premio, con una sola película, sin apenas formación y tan accesible que, en realidad, podría contratarle cualquier otra marca. Es más, vamos a ver que en los spots de nuestra muestra se manifiesta una alianza entre el autor-actor y la marca, es decir, vamos a comenzar analizando algo que, en realidad, está fuera del texto (spot), pero que explica la razón por la cual los actores de cine son utilizados frecuentemente como prescriptores.

\footnotetext{
${ }^{5}$ Consideramos al actor como autor, porque poseen unos derechos por sus obras, interpretaciones, imagen y otras ejecuciones. Al igual que los compositores y escritores, ellos son amparados por instituciones como la FIA (Federación Internacional de Actores), organismo internacional, que respalda los derechos de los actores. Trabajan a favor del actor para que puedan recibir los ingresos que se generan una vez utilizados su trabajo e imagen en los diferentes medios de comunicación. Amparados igualmente por la OMPI (Organización Mundial de la Propiedad Intelectual), luego de que se firmara en Beijing el 20-26 de junio del 2012, durante su asamblea anual, un tratado sobre la protección legal de los actores, que según el artículo publicado por la AG-IP-News "por primera vez, el nuevo tratado trae ejecutantes en el marco internacional de derechos de autor de manera integral, donde no sólo se determina el derecho a la protección de autor, sino también el derecho moral, que equivale a oponerse a modificaciones de sus obras que puedan atentar contra su reputación”. AG-IP (2012) «WIPO Beijing Treaty on Audiovisual Performances Concluded» http://www.ag-ip-news.com/news.aspx?id=28341\&lang=en. Web visitada el 12/1/2015.

${ }^{6}$ ReIs, C., \& M. Lopes, IC. (2002). Diccionario de narratología, Salamanca, Almar, 26

${ }^{7}$ Gutiérrez GonzÁlez, P. (2005). Diccionario de la publicidad, Madrid, Complutense S.A., 255

${ }^{8}$ Mondría, J. (2004). Diccionario de la comunicación comercial, Madrid, Díaz de Santos S.A., 235
} 
Por otra parte, se ha dicho, que todo relato es trabajo de un autor que interviene o se deja ver en el texto mediante diferentes rúbricas. El autor puede crear un ente ficcional, una imagen o una voz autorizada, para tratar de explicar los acontecimientos. Este ente es el narrador. Sí el autor es la persona real (el actor) el narrador es una voz ficcional delegada (el personaje). «El autor puede crear un narrador, que no exista en el mundo real, pero que indirectamente representa al creador de la comunicación» ${ }^{9}$. Esta instancia delegada, se encarga de narrar y explicar lo acaecido en la historia que se presenta. Así que la finalidad de utilizar esta instancia, se debe, por ejemplo, a la necesidad de que se explique al público lo que debe o necesita saber para la comprensión de la historia. Pues «el narrador, en cuanto entidad ficticia que dentro del escenario de la ficción enuncia el discurso, puede proyectar las actitudes ideológicas, éticas, culturales [...] del autor» ${ }^{10}$ Es decir, el autor perfila sobre el narrador lo que él quiere decir, cultivando estrategias de representación artística, a manera de alter ego. Por todo lo anterior, creemos, que el actor como autor puede delegar su voz (personaje narrador) en la imagen de unos de sus personajes que antes exteriorizó en el cine, colaborando además para que el spot juegue con la imagen transtextual, otro activo para elegir a este tipo de prescriptor.

En relación a la instancia del autor implicado o autor implícito en término moderno; o meganarrador para Gaudreault ${ }^{11}$, es un concepto inventado por Wayne Booth, quien dice que «el autor implicado es el segundo yo del autor [...], es siempre distinto del hombre real el cual crea una inversión superior de sí mismo» ${ }^{12}$. En otras palabras, se «trata de la imagen de dicho autor tal como podía ser construida por el lector a partir del texto, una imagen del autor real construida por el texto y percibida como tal por los lectores $\gg{ }^{13}$. No se puede confundir la imagen del autor implícito con la del narrador:

El autor implícito es el responsable de una actitud de armonización global de la narrativa, ejerciendo sobre el lector un efecto que es el de permitir la percepción intuitiva de un todo artístico completo ${ }^{14}$. Es la imagen que el lector se hace de la entidad autorial como responsable del conjunto del texto, como instancia que ha creado al narrador de una determinada forma, que ha optado por unos registros estilísticos, que ha definido una determinada situación, un argumento concreto etc. $^{15}$

Es decir, el autor implícito, es la imagen del autor construida por el espectador. Dicha imagen determina para nosotros la imagen de la estrella, que es:

\footnotetext{
${ }^{9}$ García Uceda, M. (2011/2001). Las claves de la publicidad (7 ${ }^{\mathrm{a}}$ ed.), Madrid, ESIC, 199

${ }^{10}$ Reis, C., \& M. Lopes, C. (2002). Diccionario de narratología, Salamanca, Almar, 156

11 Gaudreault, A. François, J. (1995). El relato cinematográfico: cine y narratología, Barcelona, Paidós

${ }^{12}$ Bоотн, W. (1978). La retórica de la ficción, Barcelona, Boch S.A, 143

${ }^{13}$ Genette, G. (1998). Nuevo discurso del relato, Madrid, Cátedra, 96-97

${ }^{14}$ Reis, C., \& M. Lopes, C. (2002), op.cit., 29

${ }^{15}$ Cabo Aseguinolaza, F., \& do Cebreiro Rábade, M. (2006). Manual de teoría de la literatura, Barcelona, Castalia, 209
} 
El actor o actriz que sustrae una parte de la sustancia heroica, divinizada y mítica de los héroes del filme, y que, recíprocamente, enriquece esta sustancia con algo suyo [...]. Cuando se habla de estrella de cine se trata pues del proceso de divinización que sufre el actor y que hace de él el ídolo de masas. ${ }^{16}$

En nuestro análisis creemos que el autor implícito la estrella es una simbiosis textual del actor (autor) y de sus personajes. Que interviene en el texto publicitario como otro activo para la marca: su imagen mítica. En el marco de la comunicación, el prescriptor se presenta como un activo, un bien para el anunciante y marca, pues así como la marca es el activo más importante (después de la gente) que el anunciante y/o compañía poseen y la ventaja principal en términos económicos ${ }^{17}$ en este artículo vamos a analizar cómo la notoriedad del actor como autor, la transtextualidad de sus personajes y poder mítico de la estrella se presentan como activos intangibles para las marcas y/o anunciantes, es decir, un recurso según las definiciones de la NIC 38 que genera valor para los anunciantes no solo en términos económicos sino también de estatus. ${ }^{18}$

\section{Metodología}

Con el objetivo de analizar cómo se presentan estas entidades (instancias narrativas) en el spot publicitario, elegimos cuarenta y un spots exhibidos entre 1990-2012 en televisión Española, y otros países europeos y norteamericanos. La propuesta de situar temporalmente el tema investigativo, se debe al continuo interés de los anunciantes en utilizar los famosos para que figuren en sus anuncios; es más, estadísticamente el número de famosos en anuncios publicitarios se ha duplicado en los últimos diez años ${ }^{19}$ a partir de 1995. En cuanto a las estrellas, solo se eligieron las que pertenecen al cine de Hollywood por ser esta industria, la más reconocida internacionalmente. ${ }^{20} \mathrm{El}$ estudio es de carácter combinado pues, por un lado, utilizaremos la técnica de análisis de contenido y de igual forma, el análisis del discurso. Como modelo de análisis se elaboraron unas tablas que contienen los datos de cada categoría de análisis ${ }^{21}$.

\footnotetext{
${ }^{16}$ Morín, E. (1972). Las stars: servidumbres y mitos, Barcelona, Dopesa, 37

${ }^{17}$ Davis, S.M. (2002). La marca: máximo valor de su empresa, México, Prentice Hall, 9

${ }^{18}$ Pérez, C. y Salina Castro, G. (2008): Valoración y evaluación de marcas: Medir para crear valor, Barcelona, Deusto

${ }^{19}$ Oкоnkwo, U (s.f) «Luxury Brands \& Celebrities: An Enduring Branding Romance», http:// www.brandchannel.com/papers_review.asp?sp_id=1234. web visitada el 15/1/2015.

${ }^{20}$ Algunos de estos famosos son: Pierce Brosnan para el anuncio de Freixenet, tarjeta Visa y Visionlab; Gerard Butler para L'Oreal, Men Expert; Sean Connery para Citroën C5, C6 y Teekanne (té e infusiones); Hayden Christensen para Lacoste Challenge; George Clooney para Nespresso; Daniel Craig para Omega; Penelope Cruz para Lancôme/Trésor; Richard Dreyfuss para Apple Inc.; Morgan Freeman para las tarjetas Visa; Jane Fonda para Age Re-perfect de L'Oreal; Harrison Ford para Lancia Lybra; Megan Fox para Giorgio Armani; Richard Gere para Audi, Ferrero Rocher; Angelina Jolie para ACNUR; Scarlett Johansson para The One de D\&G; Nicole Kidman para Chanel No5 y Schweppers Spirit; Ben Kingsley, y Helena Bonham Carter para Prada; Samuel L. Jackson para Barclays Bank; Demi Moore para Oriflame; Julia Roberts para La vie est belle de Lancôme; Kevin Spacey para American Airlines; Charlize Theron para J'Adore de Dior; Kate Winslet para American Express entre otros.

${ }^{21}$ Los datos fueron interpretados gráficamente a través del programa Microsoft Excel. No figuran dentro del artículo porque su amplitud cubriría la mayor parte del espacio.
} 
En efecto, para distinguir el nivel de notoriedad del actor como autor se eligieron tres parámetros, que para nosotros, destacan su notoriedad en función del número de películas (su filmografía), premios recibidos y su patrimonio (hasta el 2013) ${ }^{22}$. Para identificar la notoriedad de las marcas respaldadas por estos famosos y comprobar su equivalencia en cuanto a notoriedad, se valora el tiempo en el mercado, presencia en mercados internacionales y sus ventas anuales. Tocante al análisis del personaje de la estrella como narrador y sus implicaciones en el spot publicitario, se analiza su discurso iconográfico a partir de sus características biofísicas y psicológicas, las cuales nos permitirán evaluar cuáles de estos aspectos fueron usados en la prescripción y, desde luego, en la narración, pues como dice Moreno (2003) cada rasgo del personaje es un adjetivo narrativo, ya que tiene una función simbólica para materializar la personalidad de la marca, identidad, imagen, y valores ${ }^{23}$. Así mismo, se comparan los rasgos y roles de los anteriores personajes (referentes) de la estrella con aquel que figura en el spot y otros elementos narrativos que aluden a estos personajes (escenarios, retórica del color, símbolos etc.). Y por último, a fin de demostrar nuestra hipótesis de que los anunciantes contratan a actores como prescriptores porque, en tercer lugar, quieren incorporar como activo a la marca las cualidades de estrellas de esos actores, esto es, sus propiedades mercantiles, míticas, litúrgicas, y glamurosas como autores implícitos, procedimos en primer lugar, a determinar la imagen de la estrella en función de tres variables. Pues según las aportaciones de Dyer (1979), la estrella debe ser estudiada como conjunto de signos, como sistema de significantes o textos que comunican un significado al espectador. ${ }^{24}$ Estos significados los analizamos en función de los personajes referentes de la estrella, es decir aquellos personajes que han contribuido a resaltar su nivel de fama, tras el éxito de la película ${ }^{25}$. En segundo lugar, la imagen creada por la prensa escrita (periódicos y revistas), y la imagen plasmada en reseñas biográficas. Elegimos estos textos (cine, prensa, y publicidad) por ser los encargados de crear y fomentar la imagen del famoso ${ }^{26}$. De estos medios ${ }^{27}$, extrajimos aquellos calificativos que la prensa y los textos biográficos han proyectado del actor y que en el spot fueron exteriorizados. Para que se nos entienda, citamos el siguiente ejemplo: Scarlett Johansson (una de las estrellas en la muestra) más conocida por su papel en El hombre que susurraba a los caballos (1998) y Match Point (2005) fue reconocida en 2006 y 2013 por la revista Esquire como la mujer más sexy del mundo, y luego por el periódico británico The

\footnotetext{
${ }^{22}$ Los datos de la categoría de análisis notoriedad del prescriptor fueron recogidos de la fuente del prestigioso diario electrónico New York Time en la sección cine, y en la base de datos de la Celebrity Net Worth. Para medir la notoriedad de las marcas tomamos como fuente de información sus websites.

${ }^{23}$ Moreno, I. (2003). Narrativa audiovisual publicitaria, Barcelona, Paidós

${ }^{24}$ Dyer, R. (2001). Las estrellas cinematográficas: Historia, ideología, estética, Barcelona, Paidós

${ }^{25}$ Y más en concreto, personajes que le dieron a conocer entre el público, personajes y películas por la que el actor ha recibido algún premio, personajes y películas aplaudidas por la crítica cinematográfica.

${ }^{26}$ RivièRe, M. (2009). La fama: Iconos de la religión mediática, Barcelona, Critica.

${ }^{27}$ Los medios utilizados en su versión electrónica fueron: el periódico The Guardian, New York Times, las revistas Esquire, People, Time, Empire, y Hola.
} 
Guardian (2013) como el equivalente moderno de Marilyn Monroe, por sus curvas, labios carnosos, mirada y movimientos sensuales (Fig.1). Estos calificativos fueron aprovechados por Dolce \& Gabbana para mostrar su perfume The one sobre esta mítica imagen. En este sentido, la idea del anunciante se articula a partir del personaje de la estrella fusionado con los calificativos que los medios anteriormente señalados han mostrados de la actriz, condicionando de esta manera, la imagen de la estrella, esto es, el autor implícito.

Una vez reconocida la notoriedad e imagen de la estrella, pasamos a analizar cómo se exterioriza cada instancia en el spot, y la manera en que intervienen en la construcción del texto publicitario en función de una labor interpretativa y relacional que mostrará la razón por la cual son elegidas como activos para las marcas y anunciantes.

\section{La alianza de notoriedad entre prescriptor y marcas}

Los resultados arrojados de la variable notoriedad del actor, indican, que los prescriptores de nuestra muestra, tienen notoriedad, porque reúnen las cualidades de veteranía, prestigio y éxito económico. Dicho de forma cuantitativa, del $100 \%$ de las estrellas (36 actores), el 85\% goza de tener una larga trayectoria profesional, que sobrepasa las 30 películas realizadas. El $86 \%$ posee un patrimonio superior a 20 millones de dólares, y el 67\% figura con más de 30 galardones. Algunos de estos actores, como Brad Pitt, Harrison Ford, George Clooney, Nicole Kidman, Kevin Spacey, Morgan Freeman, Samuel L. Jackson, Penélope Cruz, entre otros, figuran dentro del rango de los actores mejor pagados del cine, según la revista Forbes (2013). Respecto a las marcas, tienen notoriedad, porque reúnen esas mismas características de veteranía, prestigio y éxito económico. Alrededor del $65 \%$ de las marcas sobrepasa los 30 años en el mercado, el $82 \%$ figura en cuatro y cinco continentes y el 50\% está relativamente igualado en las ventas anuales (sus ganancias sobrepasa, los 10 mil millones de euros). Teniendo en cuenta estos resultados, concebimos que los anunciantes, rueden spots con estrellas de Hollywood, porque buscan una alianza de notoriedad, una asociación que genere valor a sus marcas y esta asociación pase a ser un activo de la marca. Por tanto, si los anunciantes al elegir un prescriptor, buscan a aquellos intérpretes que tengan igual o mayor notoriedad que sus marcas, es porque no quieren aliarse con alguien que tenga un estatus menor, porque de lo que se trata, es que se produzca una alianza de notoriedad entre el actor y la marca. Dicho de otra manera, el actor de Hollywood es un activo para la marca porque suma a su estatus, el estatus de intérprete. De modo que, el actor no solo es usado por ser un referente de las tendencias sociales, sino por las múltiples posibilidades de venta que ofrece a las marcas desde la instancia narrativa como Autor. Pues de la misma forma que una empresa elige a un "gran» autor/arquitecto para levantar su sede y convertirla en marca, o una Universidad inviste a un profesional de éxito Doctor Honoris Causa, en el tipo de spot que comentamos, la empresa o la agencia de publicidad, buscan primero, un Autor-actor cuya trayectoria aporte un plus de notoriedad y credibilidad a la marca, definido en este artículo por su lista filmográfica, la cual es sinónimo de veteranía, y, por otro lado, de sus premios y patrimonio, factores que describen su éxito y, en cierto modo, lo que vale en términos 
de su caché. Todo ello (veteranía, éxito profesional y económico) pasa a ser un activo que genera y crea valor a la marca, ${ }^{28} \mathrm{o}$ si se prefiere: las empresas más veteranas, de mayor calidad y más ricas emplean actores de Hollywood porque encuentran en ellos sus mismas cualidades y con su incorporación al spot, esas cualidades se refuerzan.

\section{El activo I: La notoriedad del actor como autor}

El activo del actor como autor, llámese notoriedad, triunfo o reputación, genera una especie de retroalimentación ofeedback del que pueden beneficiarse tanto la marca como la estrella. Pues tal como lo explican los estudiosos de marketing y más concretamente Aaker pionero en el estudio de gestión de marcas, dicen que las marcas ofrecen valores a largo plazo por intermedio del nombre y de unas asociaciones que amplían o reducen las características utilitarias de los productos. Estas asociaciones tienen que ver con un sinnúmero de activos, como la calidad del producto, reconocimiento de la marca, lealtad y notoriedad otorgados por la identidad, personalidad e imagen de marca. En este sentido,

La gestión del valor de la marca enfatiza en que el valor se apoya, en gran medida, en las asociaciones que el cliente produce con la marca. Estas asociaciones pueden incluir atributos del producto, una celebridad como portavoz o un símbolo particular. Las asociaciones son conductoras de la identidad de la marca: qué es lo que la organización quiere que la marca genere en la mente del cliente. Un factor clave para construir marcas poderosas, por lo tanto consiste en desarrollar e implementar una identidad de marca. ${ }^{29}$

Estas asociaciones sirven de guía en la identidad de la marca, accediendo a que sean reproducidas y organizadas para que la marca genere buena aceptación en la mente del cliente. En efecto, la unión o dualidad que se forma entre estas dos entidades en el marco de una campaña publicitaria, genera una Alianza de Marca, un fenómeno que Bassat (1999) explica, como un indicador de calidad, que se efectúa, mediante la asociación de una marca ya consolidada con otra, para resaltar la rentabilidad de ambas y potencial su valor. En la actualidad, dicha actividad se promueve bajo el nombre de Co-Branding, donde marcas ya afianzadas, buscan otras de mayor o igual prestigio para aliarse. Por medio de esta alianza, los anunciantes no sólo buscan fortalecer la rentabilidad de sus marcas o productos, sino también, fortalecer el valor de marca, cuya actividad se hace más notoria, bien con una marca con iguales características o no. De modo que el actor de Hollywood sirve como permuta para la marca e inversamente. Pues con el interés de mantener el nivel de estrella, el famoso, debe estar en continuo movimiento y diferenciarse como dice Pringle de las estrellas inventadas ${ }^{30}$. Por esto, grandes marcas del mundo incluyendo las celebridades y políticos ya están operando bajo esta estrategia. Con lo cual, el objetivo de las estrellas al aparecer en los spots, no

\footnotetext{
${ }^{28}$ AAKer, D. (2002/1996). Construir marcas poderosas (2a ed.), Barcelona, Ediciones Gestión 2000

${ }^{29}$ AAKer, D. (2002/1996), op.cit. 26.

${ }^{30}$ Pringle, H. (2004). Celebrity Sells, John Wiley \& Sons Ltd, Chichester Inglaterra.
} 
sólo se debe a un interés económico sino también como forma de potenciar su imagen y mantener una posición en el mercado.

La notoriedad del prescriptor asociada con los de la marca, es decir, convertida en un activo de la marca, no solo subraya el valor de dicha marca en términos de su prestigio, sino que también, origina una buena comunicación en sí misma, esto es, sirve para articular el concepto narrativo del spot. Un ejemplo de esto, es Harrison Ford, quien aparece en el spot del coche Lancia Lybra titulado, «Bonsái» (2000). La idea de la campaña era comunicar el coche sobre el slogan: «El éxito no se mide por lo lejos que llegues, sino por cómo llegues». De forma implícita, el eje de esta campaña alude al éxito y notoriedad del actor como autor en correspondencia con la del coche. El spot exterioriza la exitosa trayectoria de Ford como estrella de cine, pero también como activista medioambiental del CI (Fondo Internacional) por más de 25 años. Para articular estas particularidades, muestran a la estrella rescatando un bonsái, acción que promueve al coche a través del activismo de Ford como una marca comprometida con el medioambiente (Fig.2). El mensaje del spot, promueve la notoriedad de ambas marcas y el éxito del actor pasa a ser un activo para la marca. Ocurre lo mismo con Richard Gere en el anuncio de la misma marca Lancia Delta, titulado «El poder de la diferencia» (2008). El spot se construye a partir de la imagen de Gere como activista solidario, y por otro lado, como hombre misterioso, sereno, romántico y elegante (calificativos que proyectan los medios de este), adjetivos determinados por sus personajes más representativos (de sus películas Oficial y Caballero, 1982 y Pretty Woman, 1990). La imagen del actor es proyectada para exhibir el coche bajo el lema «El poder de la diferencia». Estas particularidades en su totalidad, se presentan como un activo para la marca, y por otro lado, conforman la condición del actor como autor, ya que en el spot, Gere aparece conduciendo en la avenida Hollywood Boulevard, Los Ángeles, California, escenario que alude a la escena donde Vivian y el personaje de Gere, Edward Lewis (en Pretty Woman, 1990) se conocen, y al mismo tiempo subraya su profesión y el contexto de la estrella. De este escenario, el actor se dirige en el coche a un pueblo del Himalaya, en este espacio, Richard aparece jugando con niños y monjes budistas, mientras a sus espaldas, aparece el coche Lancia. El spot termina con un rotulo del claim que dice: "el poder de la diferencia". Estas informaciones no solo señalan su lucha por la libertad del Tíbet, sino también su ideología budista. De este modo, la estrella dispone sus ejecutantes (fama, ideología y activismo) (Fig.3), al servicio de la construcción del texto (el spot), que se aprecia en la utilización de estos escenarios y que muestran el gran diferencial de Gere como hombre de paz, gran talento, famoso por sus románticos personajes y su pasión por el budismo. Esta simbiosis textual, sirve de referencia para expresar el lema de Lancia Delta: "El poder de la diferencia".

\section{El activo II: la transtextualidad de los spots con estrellas de cine}

La muestra de los spots con estrellas del cine, reflejó, que del total general (41 spots), en el 66\% (27 spots) de estos anuncios, el famoso actor aparece exteriorizando un papel que antes hizo en la gran pantalla, o bien, el spot juega a que están ambos a la vez: el personaje y la estrella. Un ejemplo de estos spots, es el de Chanel $\mathrm{N}^{\mathrm{o}} 5$ 
con Nicole Kidman, titulado «Fuera de casa» (2004). Nicole aparece en la imagen de Satine, personaje de su Película Moulin Rouge (2001) (su presencia se distinguió, luego de analizar la identidad de este personaje en equivalencia con el que aparecía en el spot). El personaje de Nicole aparece en la enunciación del spot para señalar a través de su historia, la perdurabilidad del perfume en el tiempo, en relación al amor eterno que sentían los protagonistas del filme (Fig.4). Ahora bien, para comprender el papel del prescriptor en el relato publicitario, es necesario entender, que el prescriptor es también, un personaje de la historia que cuenta el spot. Que aparezca como personaje, no implica que no pueda, al mismo tiempo, ejercer labores de enunciación como actor o como estrella. Lo que estamos viendo, más bien, es que el prescriptor funciona a distintos niveles, que, deliberadamente, se crea una confusión sobre la instancia narrativa para alimentar esa entidad mercantil, litúrgica y mítica, esto es, la estrella o autor implícito.

Con lo cual, el análisis del prescriptor como personaje, revela que la marca concibe el concepto narrativo del spot sobre los textos fílmicos que ha interpretado el actor. Es lo que Genette en su obra Palimpsestos, llama transtextualidad ${ }^{31}$. Todo texto contiene otro texto: los spots contienen las películas que han interpretado los actores/prescriptores. En efecto, la marca contrata a un actor y lo convierte en prescriptor porque quiere vincular su producto con personajes como James Bond, Amelie, o Satine, personajes que encontramos en los anuncios de Freixenet, Chanel No5, y Schweppes (interpretados por Pierce Brosnan, Audrey Taoutou y Nicole Kidman). Esto es, porque: 1) quiere que los rasgos y los roles de esos personajes se vinculen con la marca, 2) quiere mostrar al público, que si ellos desean algo, tiene que ser, algo realmente importante y valioso para todos y 3) quiere que prescriban dentro de un relato indirecto, ya sea dando testimonio o dirigiendo la narración.

En el caso del spot de Freixenet con Pierce Brosnan como prescriptor, exteriorizan la elegante vestimenta (rasgo) de su personaje referente James Bond, sus peculiares posiciones, gestos y compañías. Para esta última, ubican un cuadro con las siluetas de unas féminas, que simbolizan la imagen de la chica Bond, y con ello muestran las típicas burbujas Freixenet (Fig.5). Para el anuncio de los refrescos Schweppes, utilizan a Satine para enunciar por medio de su frescura y belleza física las características del producto (delicado envasado y materia prima), y el lema de la campaña (Placer adulto). Para ello, recurren a la intertextualidad (una de las formas de transtextualidad) mediante la cita de la vestimenta y escenarios de la película Moulin Rouge (Fig.6). Lo mismo pasa en el spot de Chanel No5 con el mismo personaje, incluyen la situación de los personajes y los escenarios parisinos donde se desarrolló la historia romántica entre Christian, el escritor enamorado y Satine (Fig.4). Estas acciones ubican al perfume en una atmósfera romántica y entrañable, como lo fue la historia de amor de éstos personajes.

Entendemos, que aunque la prescripción del personaje no se desarrolle de forma directa, a través de lo que el espectador conoce de él, tendrá una idea sobre lo que se desea comunicar, ya que la imagen del personaje constituye unas conexiones que

${ }^{31}$ Genette, G. (1989). Palimpsesto, Madrid, Taurus 
suman cualidades positivas, pues personajes como James Bond (Pierce Brosnan) pueden comunicar conceptos relacionados con la seducción, elegancia, y osadía, o en el caso de Amelie, ella refleja la ternura, inocencia y picardía que cada mujer puede expresar cuando se pone unas gotas de Chanel (Fig.7).

Gran parte del atractivo de estos spots, radica en el juego textual que se establece entre los personajes y la narrativa del spot, al punto que hay varios niveles de lectura. Solo aquellos espectadores que conocen perfectamente al personaje y sus películas, son capaces de describir los «guiños» o las alusiones que contiene el spot. El inconveniente de esto, es que la «vida» del spot es más efímera, pues, olvidada la película, se pierde capacidad de interpretar el spot. Hay que recordar, que la elección de un prescriptor/ personaje está ligada al éxito de un filme concreto. Se aprovecha el tirón de un filme para que su protagonista se convierta en prescriptor. Si el personaje más repetido es James Bond (como sucede en nuestra muestra) es porque sus películas suelen triunfar (a menudo por una enorme campaña publicitara del filme de la que también el spot se aprovecha) y porque es un personaje muy asentado en el imaginario del espectador, en el caso de Bond, por toda una serie de novelas y películas.

En cuanto a las formas de transtextualidad que se dan en estos spots, las más repetidas son la intertextualidad y la hipertextualidad. Hay numerosas citas, directa o indirectas, y alusiones a las películas en las que ha participado la estrella. Algunos spots parecen adaptaciones, versiones, continuaciones o parodias de una película. En este sentido, el spot se vincula con una característica de la sociedad postmoderna y de su narrativa de la que hablan Lyotard ${ }^{32} y$ Vattimo $^{33}$, que es el reciclaje, la manipulación y la transformación de textos que preceden al texto. En otras palabras, el concepto narrativo se construye sobre una estética basada en lo ecléctico, el juego, la paradoja, la desintegración y hasta lo autorreferencial. Hay además, una hibridación o ausencia de límites precisos entre géneros, en el sentido de que, el spot, es también en muchos casos una historia en sí, un relato ficcional.

\subsection{La instancia del narrador personaje}

Respecto al análisis de la instancia del narrador como otra forma de presentar al prescriptor en el spot, nos dimos cuenta, que el prescriptor puede ser una entidad ficticia, dentro o fuera de la diégesis, presente físicamente (relator) o sólo como voz superpuesta, que se hace protagonista de la comunicación narrativa. En la muestra de estos spots se observó, que el prescriptor es una voz autorizada que conduce la narración, pero no explica directamente el producto. Da testimonio de un hecho, pero no certifica una propiedad. Solo existe un mensaje directo de la marca, y en algunos casos y al final del spot, cuando el prescriptor es la voz que pronuncia el claim, «el punto clave en la venta» ${ }^{34}$.

${ }^{32}$ Lyotard, J.F. (2006). La condición postmoderna, Madrid, Cátedra

33 Vattimo, G. (2000). El fin de la modernidad. Nihilismo y hermenéutica en la cultura posmoderna, Barcelona, Gedisa

${ }^{34}$ Renvoisé, P., \& Morin, C. (2006). Neuromárketing: el nervio de la venta, Barcelona, UOC, 101 
El claim resume la relación emocional que la marca pretende establecer. Esta breve frase es como su logo, la razón por la que sale al mercado. Prácticamente es el logotipo verbal [...] que encierran el beneficio principal que promete al consumidor $[\ldots]$ resumen las intenciones de una acción comercial concreta ${ }^{35}$

Quiere decir que el narrador del claim, es la voz que hace promesa de los beneficios de la marca. Pero suelen ser frases tan «poéticas» que difícilmente pueden considerarse discurso directo. En cualquier caso, es importante resaltar la alianza que se produce entre marca y prescriptor cuando esto se da. De la misma manera, un prescriptor en forma de narrador diegético y contando algo que no es más, que una historia sobre las excelencias del producto, implica un grado de simbiosis con la marca, mayor que el que se da, cuando estamos ante una narración transparente o sin narrador.

Si bien es cierto, que la estrella de Hollywood como prescriptor del spot publicitario en la instancia del narrador (y más aún como enunciador del claim) aparece en un escaso porcentaje de la muestra, lo hace enunciando el claim (la promesa y/o beneficio). Pero enunciar el claim (la promesa y/o beneficio) es sumarse sin matices a la filosofía de lo anunciado y no siempre esto es bueno ni para el actor ni para la marca. La alianza de marca se produce en el contrato mercantil, en el nivel anterior, entre el actor y la empresa, pero conviene que en el texto, el personaje y el producto guarden una ligazón «ficcional», una ilusión que se rompe cuando el personaje dice el claim, pues su enunciación es casi como romper la cuarta pared. Pero lo más importante, es que el personaje, ya sea por su carácter, por actuar como enunciador del discurso, posibilita a la marca que la transtextualidad sea otro activo.

Como hemos dicho, en más de la mitad de la muestra de los spots $(66 \% / 27)$, los prescriptores aparecían vinculados a uno de sus anteriores personajes y su presencia en el spot aludía a numerosos aspectos del filme como: espacios, objetos, argumento, tono, etc. Esto quiere decir, que estos spots operan, como hemos dicho, con el concepto de transtextualidad. Con lo cual, en este apartado, logramos identificar que los spots guardan cierta relación con los filmes de estos famosos porque las marcas quieren relacionar sus productos con algún rasgo, rol, puesto narrativo o función enunciativa de los personajes interpretados por el prescriptor y que ya son reconocidos por el público. En otras palabras, los prescriptores son elegidos porque: 1) el carácter de sus personajes (lo masculino) encajan perfectamente en aquello que se anuncia; 2) sirven como especie de arquetipo y ese arquetipo (el héroe) permite construir el principio del placer: el motor del deseo hacia el producto y la marca; y 3 ) quiere en algunos casos, que el prescriptor prescriba, ya sea contando la narración o subrayando el claim, pues de este modo, consigue que el activo esté vinculado al nombre y símbolo de la marca. Todo esto, decíamos, sitúa a estos spots en lo postmoderno, en el sentido de que todo puede combinarse con todo o, como sucede en la muestra analizada, se practica la apropiación y el reciclaje textual de las películas que el prescriptor ha interpretado.

\footnotetext{
${ }^{35}$ Navarro Gutiérrez, C. (2010). Creatividad publicitaria eficaz: Cómo aprovechar las ideas creativas en el mundo empresarial, Madrid, ESIC, 120-123
} 


\section{El autor implícito: la estrella}

Tal como se expuso, el autor implícito, la estrella, se presenta en el spot como la instancia enunciadora que se encarga de prescribir sobre la marca o producto desde sus diferentes posibilidades de comunicación, es decir, desde aquella imagen que del actor se proyecta, por su filmografía, la imagen que el espectador se crea del actor a partir de sus trabajos en cine, televisión, prensa, publicidad, etc. En la construcción del texto publicitario esta imagen se exterioriza en el $66 \%$ de los casos a través de su personaje referente o algún personaje de su lista filmográfica. En el 34\% restante de los spots, la estrella participa a partir de su imagen solidaria y por medio de algún calificativo de la prensa y/o reseñas biográficas. Sin embargo, a pesar de este resultado e interpretación de datos, se observó, que el autor implícito no aparece en una única imagen, siempre proyecta la imagen fusionada entre las tres variables que se han estudiado. De hecho, como resultado de esta "fusionalidad" es que se conoce la existencia de La Estrella o Autor Implícito y su efectividad en el texto publicitario.

Cabe destacar, que una de las formas en presenciar la prescripción del personaje de la estrella, fue a través de la referencia del espacio, que como dice Sánchez Navarro, aparte de contener a los personajes, se convierte en un signo de valor, ya que dependiendo del vínculo emocional que se creó con el espectador en la obra, el espacio puede servir de interpretación para recordar los acontecimientos de los personajes ${ }^{36}$. Al mismo tiempo, puede funcionar como metonimia o metáfora para reflejar el estado de ánimo de los personajes, describir algún evento de la narración, o describir el universo representativo del personaje. Aunque el espacio en el cine sea uno, puede tener dos funciones y por consiguiente dos valores:

Se habla del espacio explícito (geográfico o geométrico), se puede medir, es un espacio descriptivo, y en segundo lugar cumple una función dramática, es un espacio expresivo. En su función descriptiva se limita a contener cada una de las acciones de la película. Presentando todos los elementos de la ciudad, de una llanura del Oeste etc. El dramático es el que expresa las situaciones y sugiere el ambiente. Se utiliza para localizar y concretar las psicología de los personajes, sus ideas y sentimientos en diversas situaciones. El paisaje y el decorado, la iluminación, la tonalidad y el colorido expresan y subrayan el carácter, la alegría, o la tristeza de la acción que entonces tienen lugar en ese espacio ${ }^{37}$.

La función del espacio no es inerte, sino que resulta de importancia para la narración, y «Consiste en asumir la función de una prolongación psicológica de los personajes, proyectando su estado de ánimo. Ya que en el espacio fílmico existe una relación entre los personajes con el espacio que se representa ${ }^{38}$. Un ejemplo de esto, lo vemos en la película Thelma y Louise (1991), del director Ridley Scott, cuando en la penúltima secuencia, se percibe, por medio del paisaje, la continuidad de los sentimientos de los

\footnotetext{
${ }^{36}$ SÁnchez Navarro, J. (2006). Narrativa audiovisual, Barcelona, UOC

${ }^{37}$ Fernández Díez, F. y Martínez Abadía, J. Manual básico de lenguaje y narrativa audiovisual, Paidós, 1999 p. 65-67

${ }^{38}$ García Jiménez, J. (1996/1993): Narrativa audiovisual (2ª ed.), Madrid, Cátedra, S.A. p. 350
} 
personajes (Thelma y Louise), a través de los extraordinarios planos generales que enfocan un inmenso cielo azul y un espacioso desierto que expresa lo que sienten y persiguen dichos personajes: la búsqueda de la libertad. Lo que indica, que el espacio en tanto tiene una función situacional, o referencial, igualmente refleja la psicología de los personajes. Con lo cual, el autor implícito con la idea de ejemplificar lo que sentía su personaje, tomó el espacio como símbolo de su existencia. Un ejemplo de esto, lo encontramos en el spot de Chanel $\mathrm{N}^{\circ} 5$ con Audrey Tautou, titulado Tren de noche (2009), donde recurre al tren que en Amelie sirvió como elemento narrativo para representar la transformación del personaje. El tren representaba el viaje interno y externo de Amelie. Cada viaje en tren de su casa a la de su padre y viceversa representaba el cambio emocional de la niña a mujer, pero además, recuerda la historia de amor de Amelie y Nino (personaje secundario de la película). Por ello, la inclusión de este espacio (tren) en el spot, sirve para configurar un sinnúmero de informaciones que favorecen a la marca y/o producto anunciado. Lo mismo ocurre, con la narrativa del estilismo (rasgo físico del personaje), que «expresa la identidad del personaje en términos de su: profesión, nivel social, geográfico, sus debates internos, personalidad etc. $\rangle^{39} \mathrm{Y}$, por otro lado, la utilización de la música de la película para aludir a la imagen o acontecimiento del personaje, la utilización de los planos, la fotografía, objetos simbólicos, posiciones etc. (Fig. 8), fueron expuestos en el spot publicitario para denotar la presencia del autor implícito para diversos fines:

1. A través del personaje, aparte de ser una marca registrada, su rol y variedad de rasgos, permite vender el producto bajo cualquier clave de: seducción, elegancia, estilo, aventura, ternura etc.

2. Al igual que la figura de la cenicienta, el mentor, el héroe, etc., forman parte del inconsciente colectivo, los personajes del autor implícito forjan la perennidad de la estrella, unido a los calificativos que la prensa ha creado de este.

Entendimos, que la finalidad del autor implícito, en cualquier faceta, puede deberse a la necesidad de emitir un significado con aquello que se desea comunicar. Es decir, si Lancia (anunciante) desea comunicar la versatilidad y sobriedad en el diseño de su automóvil, entonces será necesario escoger la imagen de la estrella que mejor convenga. Algunas veces será necesario acudir al personaje, otras veces a la imagen que ha creado fuera de la pantalla. Y en otras ocasiones la fusionará.

\section{El activo III: el poder del mito}

La presencia del autor implícito (la estrella) en el spot publicitario, se debe, no sólo a la necesidad de la marca de ser respaldada a partir del atributo o rol del personaje, o aquella imagen reconocida por el espectador y creada por la prensa, sino también por la necesidad de la estrella en ser reconocida a través de la marca, creando un contexto donde ambas imágenes se unen para crear una sola imagen que participa una de la otra y que, a su vez, es mezclada por el imaginario del espectador para hacer de ella un significado como ocurrió en el posicionamiento de Chanel con Marilyn Monroe en los

${ }^{39}$ JuÁrez Almendros, E. (2006). El cuerpo vestido y la construcción de la identidad en las narrativas autobiográficas del Siglo de Oro. Rochester, USA, Tamesis Books, 198 
años 50` o Christian Dior con Marlene Dietrich en la década de los 40`. Estas marcas no venden solo un atributo del producto, sino más bien, un status o un rasgo de aquellas estrellas que en su momento prescribieron para la marca. La imagen (lo que percibe el espectador) de ambas marcas está íntimamente en el recuerdo de sus espectadores y permite el disfrute del mismo universo mítico. Porque la estrella es un mito. Y, «el mito es una forma de comunicación que se alimenta de comunicación ${ }^{40}$ la marca por su lado, se alimenta del universo estelar del actor de Hollywood, un universo textual, mezcla de biografía y personajes. Pero lo relevante de esto, es que «hay tres formas de leer el mito: estructural, cínica y desmitificadora $»^{41}$.

La lectura estructural es la propia del espectador. El público no ve el mito como un discurso sino como hechos. Para él una estrella es un ser en parte verdadero (lo biográfico) y en parte irreal (lo fílmico, lo mediático), pero para él siempre aparece algo natural: coloca el poster de su estrella favorita en su habitación, colecciona sus películas, sigue sus noticias en la prensa, copia su peinado o su forma de vestir, etc. La lectura cínica, en cambio, es la del autor que concibe el mito, la de la marca. Ésta transforma un sentido en forma, esto es, convierte un concepto de venta en un concepto narrativo; en este caso, hace del prescriptor una estrella, un mito. El mito es una construcción narrativa, que, en este caso, se opera al transformar al actor de Hollywood en un artefacto cultural: en una estrella. En esta segunda lectura, el mito es un instrumento muy poderoso, pues sirve para pregonar un contenido y para venderlo. Es la forma de actuar del productor de mitos, aquí, de las marcas.

Finalmente, la lectura desmitificadora desenmascara el contenido, descifra el mito, su discurso, y comprende su impostura. Los mitos no son naturales sino que los crea el hombre con una intención concreta. Esta lectura es la que se ha hecho en estas páginas.

La estrella es siempre una apropiación o reciclaje de textos. El productor de mitos transforma un sentido ya existente en forma. La marca convierte al actor de Hollywood en concepto de venta por medio de un texto, el spot, que es suma transtextual de otros textos del actor: películas, biografías, noticias de prensa, carteles, entrevistas en la radio, etc. Todos ellos crean el universo mítico de la estrella y hacen que dicho universo parezca accesible con la compra del producto. Con lo cual, en la hipótesis del autor implícito o estrella, descubrimos que el $98 \%$ de los spots, el concepto narrativo se articuló sobre la imagen de la estrella a partir de la asociación o simbiosis textual de la imagen del actor y sus personajes. Es decir, el autor implícito participó en la producción o elaboración del enunciado con una función claramente narrativa desde una imagen fusionada que proviene de su filmografía, de sus ejecutantes fuera de la pantalla y, por otro lado, de la imagen que la prensa ha divulgado de la estrella. Esta unión textual convierte al actor en estrella: en mito.

Los textos del prescriptor enriquecen narrativamente el spot generando un tipo de prescripción que juega con lo transtextual y el imaginario colectivo. Por eso es posible

\footnotetext{
${ }^{40}$ Barthes, R. (2012). Mitologías, Madrid, Biblioteca Nueva, 221

${ }^{41}$ Ibidem, 221
} 
que una actriz muerta como Marilyn Monroe pueda todavía ser prescriptora, como también lo podrían ser Marlene Dietrich, Cary Grant y tantos otros actores clásicos del cine.

\section{Conclusiones}

En este artículo, nos propusimos analizar que, la venta de productos y de marcas por medio de spots publicitarios en los que se usan estrellas de cine de Hollywood como prescriptoras, no tienen necesariamente que hablar de una forma directa de las cualidades del producto, pueden prescribir desde otro concepto narrativo más sutil: a través de las instancias enunciadoras o discursivas. En efecto, hemos mostrado que el prescriptor es un concepto narrativo que articula el spot publicitario en tres niveles: el autorial, en la imagen o prosopografía de algunos de sus personajes y, en ocasiones, como narradores y por último como autor implícito.

La prescripción en este tipo de spot se articula, por lo tanto, sobre el estatus del actor, sobre la imagen textual de los personajes que ha interpretado y sobre la suma de ambos elementos: su imagen de estrella. Con ello, los anunciantes consiguen transferir a la marca y al producto tres activos: la notoriedad del actor, la transtextualidad del personaje y el poder mítico de la estrella, que es en sí misma un texto, un concepto híbrido, que en la elaboración del spot juega con el despiste, la confusión, lo espectacular, lo ficcional, lo legendario y como decíamos, con lo transtextual. El autor implícito-la estrella se proyecta como una imagen armonizada entre su rol como autor de sus propias palabras (trabajos/notoriedad), sus personajes como sello particular, y aquella imagen construida por los medios y concebida por el propio espectador. Como resultado de todo ello, el texto publicitario se convierte en un metatexto que guarda a través de la imagen de la estrella relación con otros textos, donde incluye sin parecer que lo hace, los comentarios de los textos de prensa (periódicos, revistas), televisión, el cine (los filmes donde actúa el actor), comentarios biográficos, citas de documentales sobre el actor, alusiones a fotografías, apariciones públicas etc.

En definitiva, podemos decir, que la prescripción parte de un proceso de transferencia de significados que incluye: 1) la notoriedad del autor (la persona/el actor), 2) la transtextualidad de los personajes; y 3) la suma de ambas: el poder del mito (de la estrella). Según el proceso de transferencia de significados de McCracken (1989), cuando el receptor reconoce las características y el mensaje contenido en estas tres instancias, éste comenzaría la fase de construcción, interpretación y relación con lo anunciado $^{42}$. Pero siempre dentro de lo que Barthes (1988) llama, lectura estructural ${ }^{43}$. El mensaje contenido en el spot sirve de orientación para que el receptor asuma al actor como un mito sin darse cuenta de que tal mito es una realidad solo textual creada por la marca.

\footnotetext{
${ }^{42}$ Mccracken, G. (1989). "Who is the celebrity endorser? Cultural foundations of the endorsement process», Journal of Consumer Research, 16 (3), 310-321.

${ }^{43}$ Barthes, R. (1988): Análisis estructural del relato, México, Premiá.
} 
El propósito de trabajar con lo transtextual no radica en subrayar la originalidad en la elaboración del texto publicitario, ni en contribuir en el desarrollo de una nueva tendencia narrativa que parte del reaprovechamiento de textos precedentes o la supervivencia de importantes industrias que guardan estrecha relación con estos textos, sino más bien, en favorecer un reciclaje de textos que ayuda a alimentar el mito. Es decir, el concepto narrativo del spot se edifica sobre una estética basada en un pensamiento postmoderno.

Y volviendo a la idea de posmodernidad, se dice que una característica de ella, es que, el texto llega a sustituir la realidad porque nos pasamos el día mirando las pantallas, es decir, deseamos, más que por la experiencia directa, por lo que las pantallas dicen que debemos desear. Esto nos lleva, precisamente, a la estrella, que no es más que eso: un texto donde se confunden el actor y sus personajes, esto es un mito. Esta construcción es posible, porque además, en el mundo postmoderno se han producido cambios en la sociedad y en el lenguaje. Lo individual (rito al cuerpo, liberación personal, subjetivismo, etc.) ha desplazado a lo colectivo y ha creado una especie de su "súper ello": la estrella. La economía productiva ha sido sustituida por la economía de consumo y hasta por el consumo compulsivo. Es más, la industria del consumo aliada con la industria de los medios se han convertido en centro de poder, de hecho, los medios son lo que hacen que algo exista (incluidas las marcas) y los que han sustituido a los grandes líderes carismáticos por las estrellas. En cuanto al lenguaje, el arte con mayúsculas ha sido sustituido por el arte popular o alternativo (el cine, la música, el cómic...), el cómo de los mensajes importa más que el qué, el entretenimiento, más que la información, la imagen de los líderes (o de las marcas) más que su ideología, y el arquetipo, más que el personaje complejo. Además, la que hemos llamado lectura estructural del mito, la lectura que realiza el espectador, concuerda con otra característica de la sociedad postmoderna: el giro lingüístico. Este giro consiste en sostener que el lenguaje no son las palabras o las imágenes que designan la realidad sino que son la realidad. Por eso, se afirma, el lenguaje moldea nuestro pensamiento y no puede haber ningún pensamiento sin lenguaje. El lenguaje como dice Palti (1988) crea literalmente la verdad.

En definitiva, las estrellas de Hollywood en el spot publicitario, por ser una manifestación de lo individual, lo mediático, lo discursivo y el giro lingüístico, corroboran en que son una realidad de la sociedad postmoderna. Lo que compra el consumidor no es el producto en sí, sino la posibilidad de formar parte de un mundo maravilloso (mítico, textual), el del prescriptor-estrella, donde siempre parece cumplirse el principio del placer. Dada esta sociedad postmoderna, la estrella de Hollywood, que, insisto, es una pura entidad mediática, que solo existe como texto, puede vender mucho y bien, y convertirse en activos para las marcas. 


\section{Bibliografía}

AAKer, D. A. (1994): Gestión del valor de la marca: Capitalizar el valor de la marca, Madrid, Díaz de Santos.

- (2002/1996): Construir marcas poderosas ( $2^{\mathrm{a}}$ ed.), Barcelona, Ediciones Gestión.

AG-IP NEWS. (2012): «WIPO Beijing Treaty on Audiovisual Performances Concluded» http://www.ag-ip-news.com/news.aspx?id=28341\&lang=en. Web visitada el 12/1/2015.

BARTHES, R. (1988): Análisis estructural del relato, México, Premiá.

- (2012): Mitologias, Madrid, Biblioteca Nueva.

BASSAT, L. (1999): El libro rojo de las marcas, Madrid, Espasa Calpe, S.A.

Bоотн, W. (1974): La retórica de la ficción, Barcelona, Boch S.A.

Cabo Aseguinolaza, F., \& do Cebreiro Rábade, M. (2006): Manual de teoría de la literatura, Barcelona, Castalia.

Cochrane, L. (2013): «How Hitchcock's women cast a spell on fashion season after season», http://www.theguardian.com/fashion/2013/jan/15/hitchcock-womenfashion-designers. Web visitada 8/1/2015

DAvis, S.M. (2002): La marca: máximo valor de su empresa, México, Prentice Hall.

Diez Puertas, E. (2006): Narrativa filmica: Escribir la pantalla, pensar la imagen (2a ed.), Madrid, Fundamentos.

DYeR, R. (2001): Las estrellas cinematográficas: Historia, ideología, estética, Barcelona, Paidós.

Fernández Díez, F., y Martínez Abadía, J. (1999): Manual básico de lenguaje y narrativa audiovisual, Paidós.

Fernández Díez, F. (2005): El libro del guion, Madrid, Díaz de Santos.

GARCíA JiMÉNEZ, J. (1996): Narrativa audiovisual (2a ed.), Madrid, Cátedra, S.A.

García UCEDA, M. (2011/2001): Las claves de la publicidad (7ª ed.), Madrid, ESIC.

Gaudreault, A. François, J. (1995): El relato cinematográfico: cine y narratología, Barcelona, Paidós

Genette, G. (1989): Palimpsesto, Madrid, Taurus.

- (1998): Nuevo discurso del relato, Madrid, Cátedra.

Gutiérrez GonzÁlez, P. (2005): Diccionario de la publicidad, Madrid, Complutense S.A.

JuÁRez Almendros, E. (2006): El cuerpo vestido y la construcción de la identidad en las narrativas autobiográficas del Siglo de Oro, Rochester, USA, Tamesis Books.

Lyotard, J.F. (2006): La condición postmoderna, Madrid, Cátedra.

MCCRACKen, G. (1989): «Who is the celebrity endorser? Cultural foundations of the endorsement process», Journal of Consumer Research, 16 (3), 310-321.

Mondría, J. (2004): Diccionario de la comunicación comercial, Madrid, Díaz de Santos S.A.

Moreno, I. (2003): Narrativa audiovisual publicitaria, Barcelona, Paidós.

Morín, E. (1972): Las stars: servidumbres y mitos, Barcelona, Dopesa.

Navarro Gutiérrez, C. (2010): Creatividad publicitaria eficaz: Cómo aprovechar las ideas creativas en el mundo empresarial, Madrid, ESIC.

NEW YORK TIME, New York Time online, http://www.nytimes.com/pages/movies/ 
index.html. Web visitada 10/1/2015.

Окоnкwо, U (s.f) «Luxury Brands \& Celebrities: An Enduring Branding Romance», http://www.brandchannel.com/papers_review.asp?sp_id=1234. web visitada el $15 / 1 / 2015$.

Palti, E. J. (1998): Giro lingüístico e historia intelectual: Stanley Fish, Dominick Lacapra, Paul Rabinow y Richard Rorty, Buenos Aires, Universidad Nacional de Quilmes.

Pérez, C. y Salina Castro, G. (2008): Valoración y evaluación de marcas: Medir para crear valor, Barcelona, Deusto

Pringle, H. (2004): Celebrity Sells, John Wiley \& Sons Ltd, Chichester Inglaterra

Pomerantz, D. (2013): «Angelina Jolie Tops Our List Of Hollywood's Highest-Paid Actresses», http://www.forbes.com/sites/dorothypomerantz/2013/07/29/angelinajolie-tops-our-list-of-hollywoods-highest-paid-actresses/. Web visitada 5/1/2015

ReIs, C., \& M. Lopes, †. C. (2002): Diccionario de narratología, Salamanca, Almar.

Renvoisé, P., \& Morin, C. (2006): Neuromárketing: el nervio de la venta, Barcelona, UOC.

Rivière, M. (2009). La fama: Iconos de la religión mediática, Barcelona, Crítica.

SÁncheZ NAVARro, J. (2006): Narrativa audiovisual, Barcelona, UOC.

VAtтimo, G. (2000): El fin de la modernidad. Nihilismo y hermenéutica en la cultura posmoderna, Barcelona, Gedisa. 
Anexos: Figuras y fotogramas de los spots

Fig. 1. La imagen de Scarlett Johansson exhibida en el spot de Dolce \& Gabbana como el equivalente moderno de Marilyn Monroe.

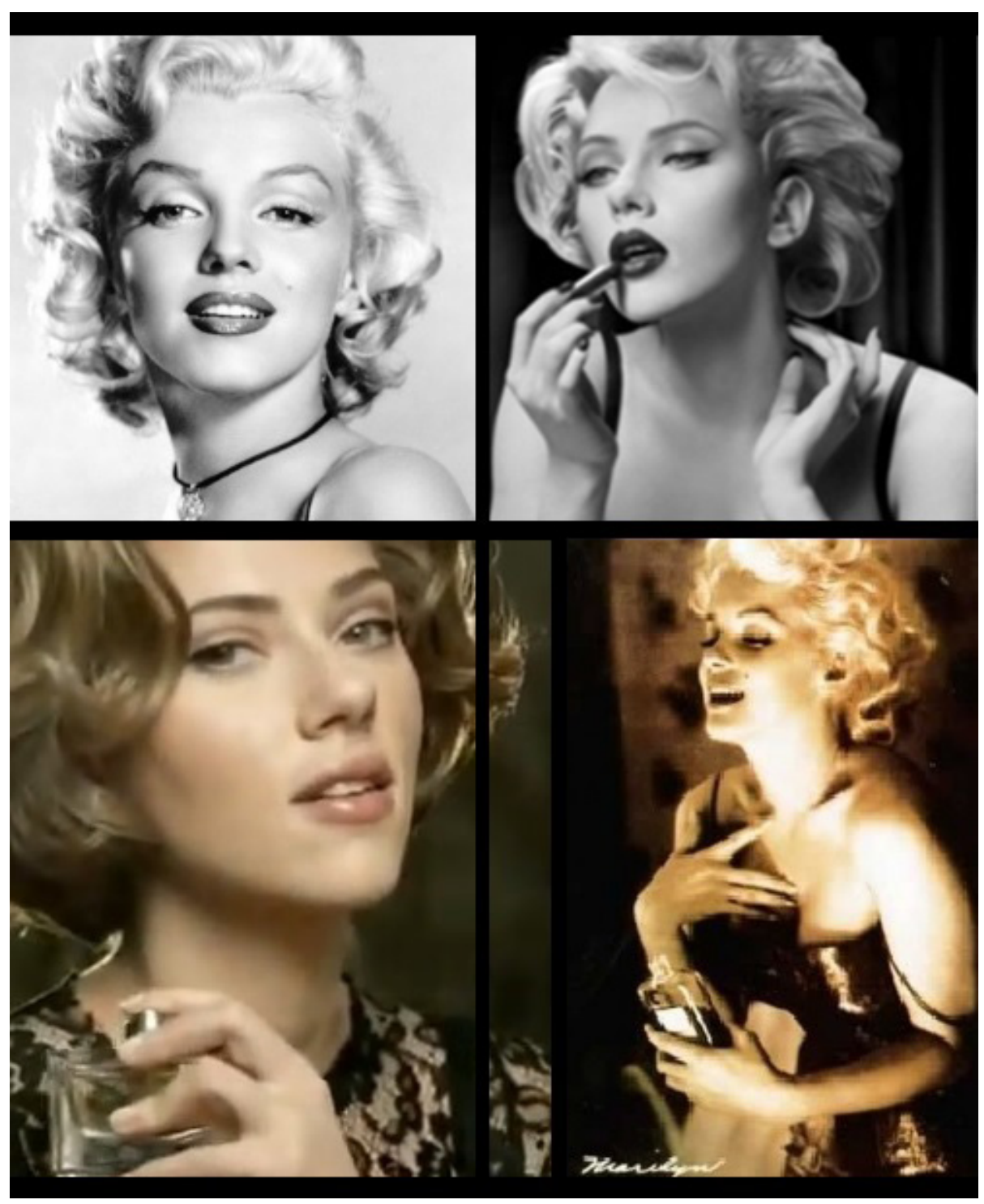


Fig. 2. El activismo de Harrison Ford articulado en el spot de Lancia Lybra

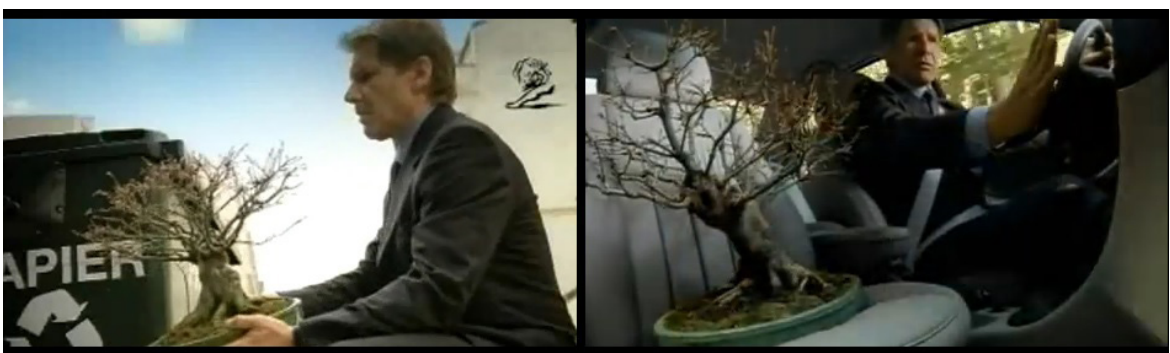

Fig. 3. El activo de Richard Gere para Lancia Lybra: fama, ideología y activismo
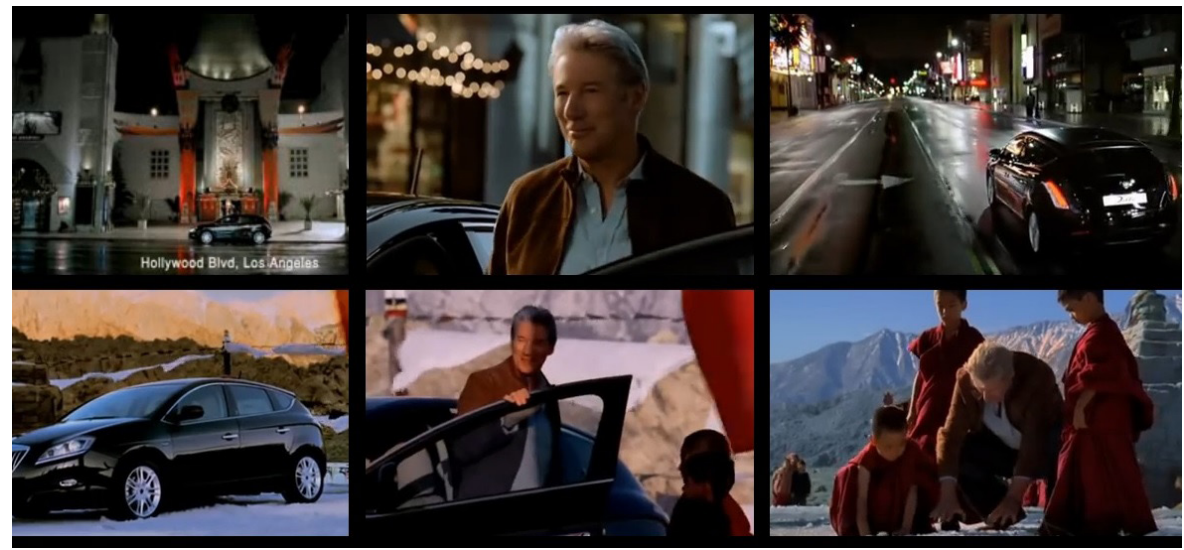

Fig. 4. Fenómeno transtextual: La película Moulin Rouge (2001) citada en el spot de Chanel $N^{0} 5$

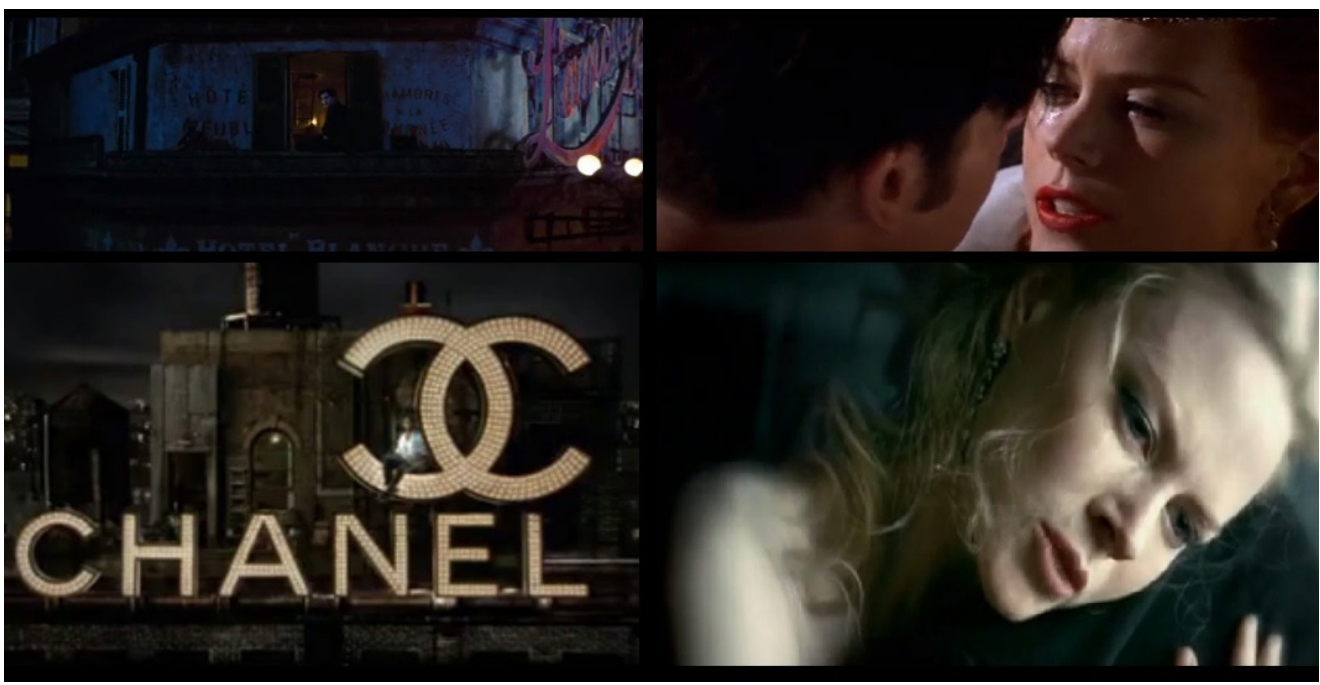


Fig. 5. Fenómeno transtextual: Alusión al personaje James Bond en el spot de Freixenet

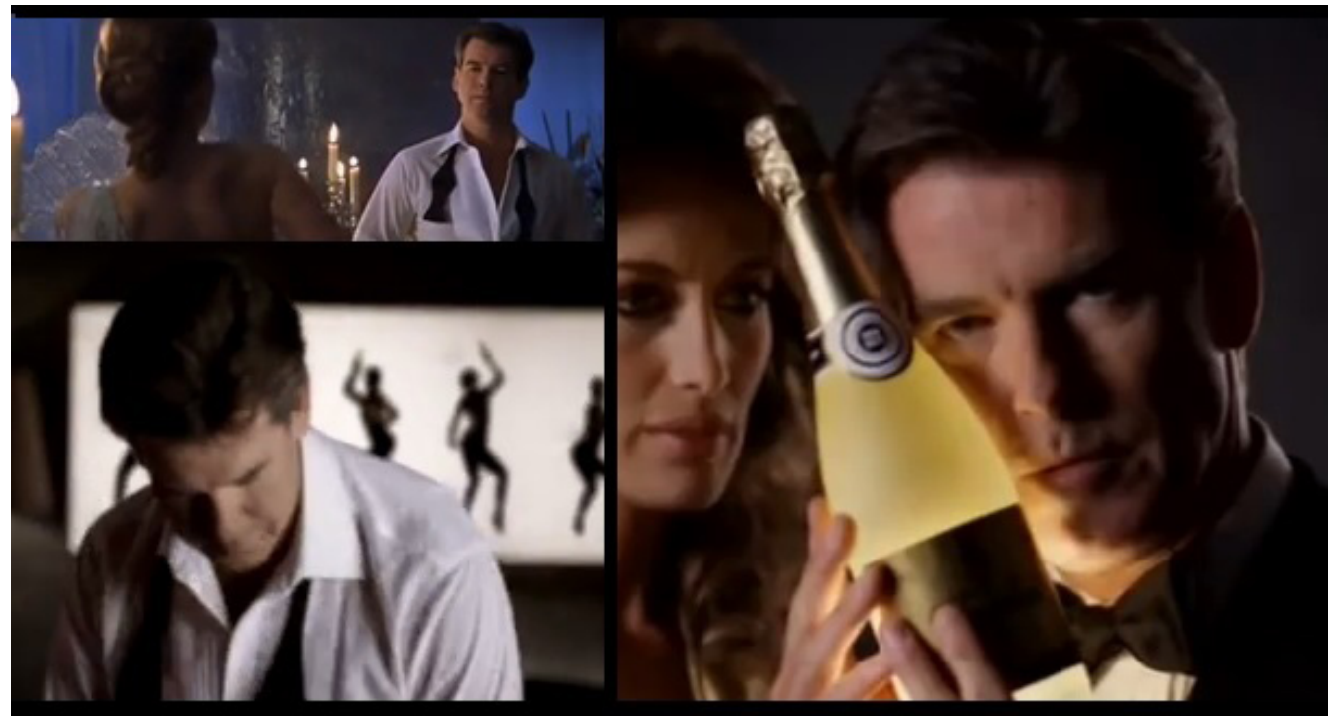

Fig. 6. Fenómeno transtextual: La película Moulin Rouge (2001) en el spot de Schweppes

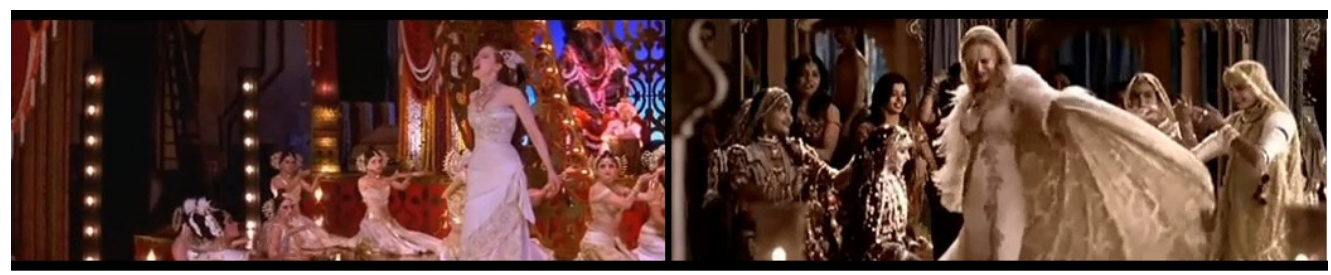

Fig. 7. Fenómeno transtextual: La película Amélie (2001) citada en el spot de Chanel $N^{\circ} 5$

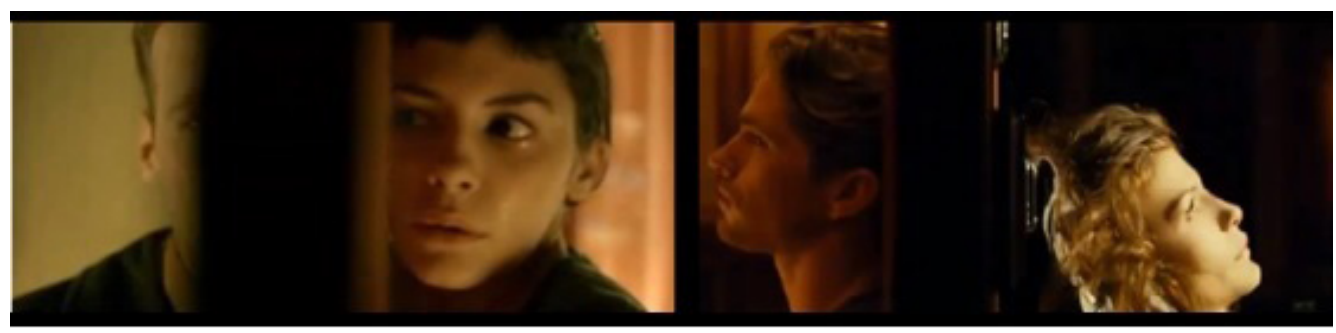


Fig. 8. Elementos simbólicos de la película Amélie (2001) en el spot de Chanel $N^{\circ} 5$

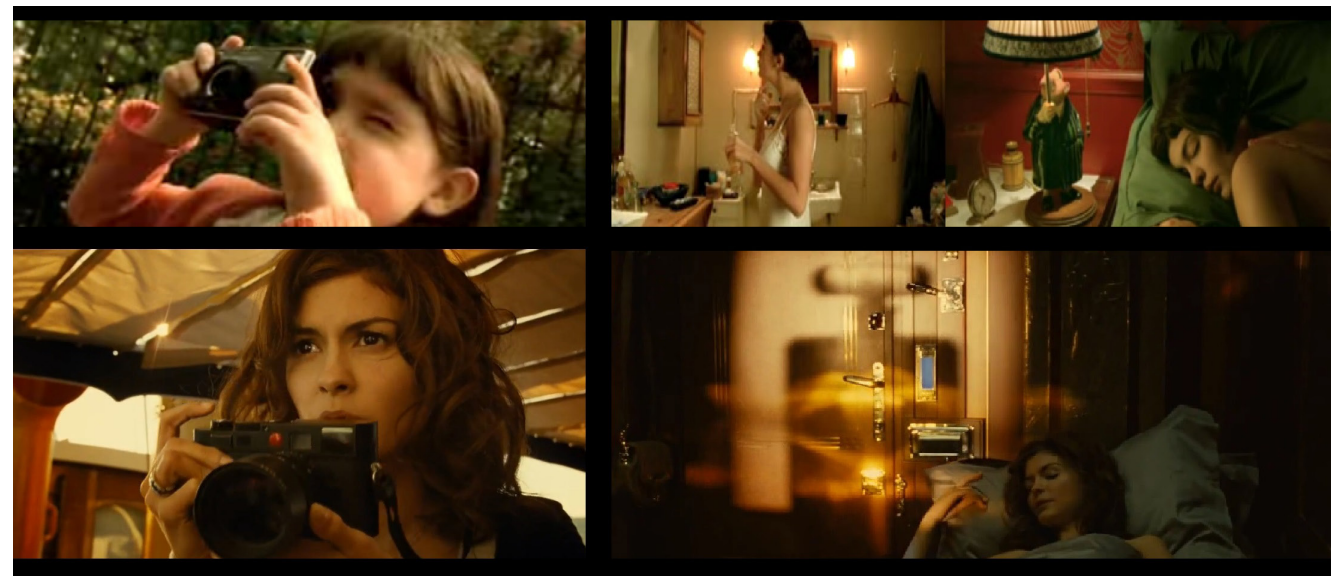

